\title{
INFLUÊNCIA DA GRANULOMETRIA NO PROCESSO DE EXTRAÇÃO DO ÓLEO ESSENCIAL E COMPOSIÇÃO QUÍMICA DE Croton Cajucara Benth (EUPHORBIACEAE)
}

\author{
I. G. R. SILVA ${ }^{1}$, E.M. SOUSA ${ }^{1}$, M. L. SANTOS ${ }^{1}$, A.B.C. MASCARENHAS ${ }^{1}$ D. S. B. \\ BRASIL $^{1}$, E.H.A.ANDRADE ${ }^{1}$ \\ ${ }^{1}$ Universidade Federal do Pará \\ E-mail para contato: izabellagrend @ gmail.com
}

RESUMO - A extração e análise da composição química do óleo essencial da casca do espécime Croton cajucara (Benth), da família Euphorbiaceae, é importante para o aprimoramento de suas propriedades características a fim de beneficiar a população e a agroindústria. O objetivo deste trabalho foi avaliar, com base na variação da granulometria via peneiramento, o rendimento, feito por hidrodestilação e a composição do material, através da cromatografia de fase gasosa acoplada a Espectrometria de massas (CG/EM), para que se tenha um controle de qualidade e eficiência na obtenção do óleo da "Sacaca", como é popularmente conhecida. E este tem demonstrado um considerável potencial em aplicações industriais, por conta de sua significativa atividade antimicrobiana e antioxidante. Diante dos resultados, obteve-se que, a partir das granulometrias classificadas, não houve alteração significativa no rendimento, porém, na análise da composição química, observou-se tal diferença. Linalol, Espatulenol e $\alpha$-Gurjuneno atuaram como componentes majoritários, contribuindo para suas atividades antiulcerogênica, antiinflamatória e antinociceptiva.

Palavras chaves: Croton cajucara, hidrodestilação, rendimento.

\section{INTRODUÇÃO}

Óleos essenciais são misturas complexas que em temperatura ambiente apresentam aspecto oleoso, tendo como principal característica a volatilidade. Frequentemente apresentam odor agradável e marcante, geralmente incolores ou levemente amarelados, com sabor ácido e picante, pouco estáveis em presença de luz, calor e ar, além de serem pouco solúveis em água. (SIMÕES \& SPITZER, 1999; SAITO \& SCRAMIN, 2000).

Croton cajucara Benth, pertencente à família Euphorbiaceae, pode ser frequentemente encontrada na região Norte do Brasil. Na Amazônia, a planta é popularmente conhecida como Sacaca e significa "feitiço" na língua Tupi, além de representar um recurso medicinal de extrema importância no tratamento de algumas doenças. No geral, a folha e a casca da planta em questão são utilizadas de forma empírica pela população na forma de chá, para o tratamento de diabetes, diarréia, malárias, febre, distúrbios gastrintertinais, renais, hepáticos e no controle de níveis elevados de colesterol (Costa et al. 1989).

A operação de peneiramento é essencial no âmbito das indústrias que manuseiam produtos granulados (OROFINO, 2012), os quais ao serem inseridos no mercado, devem apresentar granulometria específica de acordo com sua aplicação. Dessa forma, o conhecimento do diâmetro representativo de uma amostra de partículas é de suma importância, seja no controle de qualidade de produtos ou na identificação da eficiência de uma operação unitária. 
Portanto, o objetivo do presente artigo foi avaliar a influência da granulometria no rendimento e composição química do óleo essencial da espécie C. cajucara, utilizando as técnicas de hidrodestilação e cromatografia gasosa acoplada a espectrometria de massas (CG/EM), respectivamente.

\section{MATERIAIS E MÉTODOS}

\subsection{Preparação do material para a extração do OE.}

Cascas de $C$. cajucara foram coletadas de um espécime localizado no município de Peixe Boi (PA) e submetidos à secagem em estufa com circulação forçada à $34^{\circ} \mathrm{C}$ por 3 dias, sendo posteriormente triturado em moinho de facas. Em seguida, o material foi submetido a análise granulométrica por meio de um conjunto de 9 peneiras da série \#Tyler (\#6, \#9, \#10, \#12, \#14, \#20, \#24, \#28, \#32) e o fundo. Assim, pesou-se as massas das peneiras vazias previamente lavadas e secas em estufa por $24 \mathrm{~h}$. A série de peneiras foi colocada em ordem descrescente de diâmetro de abertura das malhas, tomando como referência o topo da pilha de peneiras. $\mathrm{O}$ sistema de agitação mecânica foi ligado por 5 minutos. Ao final do processo de agitação, as peneiras foram novamente pesadas juntamente com as respectivas massas retidas e distribuídas em granulometria: fina, média e grossa.

\subsection{Cálculo do diâmetro médio}

Através dos dados obtidos pelo sistema de peneiramento, tem-se as massas da peneira vazia e cheia e seu diâmetro médio ( $\mathrm{mm})$, exposto na Tabela 1 . Em seguida, determinou-se a massa retida, $\%$ retida, $\%$ passante, $\%$ retida acumulada e $\%$ passante acumulada pelas seguintes equações:

$$
\begin{gathered}
\% \text { Retida }=\frac{m_{\text {retida }}}{m_{\text {total }}} * 100 \\
\% \text { Passante }=\frac{m_{\text {total }}-m_{\text {retida }}}{m_{\text {total }}} * 100 \\
\% \text { Retida Acumula }=\% \text { Retida }+\% \text { Retida nas peneiras anteriores } \\
\% \text { Passante Acumula }=1-\% \text { Retida Acumulada }
\end{gathered}
$$

Os resultados obtidos (Tabela 2), foram usados para o cálculo do diâmetro médio (Gráfico 1), através das interceções das curvas em função da \%acumulada e abertura (mm).

\subsection{Determinação da umidade residual}

Determinar a umidade garante a eficiência da extração do óleo essencial. Assim, o teor de umidade da biomassa foi calculado em porcentagem de água nas amostras estudadas utilizando a balança determinadora de umidade com aquecimento por infravermelho.

\subsection{Extração do Óleo Essencial da Croton cajucara}

Para a extração do óleo essencial da planta em estudo, foi utilizado o método de hidrodestilação no laboratório de Produtos Naturais, da Faculdade de Engenharia Química (Universidade 
Federal do Pará), utilizando sistema Clevenger modificado acoplado ao condensador entre 10$15^{\circ} \mathrm{C}$, durante $3 \mathrm{~h}$ após ser estabelecido à fervura através da manta aquecedora. Separou-se em três extrações, de acordo com a granulometria, com uma massa de $60 \mathrm{~g}$ em cada balão. Garantindo assim a comparação desejada.

\subsection{Rendimento do óleo essencial}

O cálculo do rendimento do óleo em base livre de umidade (BLU), equação 5, foi feito através da relação entre massa, óleo e umidade:

$$
\text { \%óleo BLU }=\frac{\text { Volume do óleo obtido }(\mathrm{ml})}{\text { massa }(\mathrm{g})-\left(\frac{\text { massa } \times \text { umidade }}{100}\right)} \times 100
$$

\subsection{Identificação dos componentes químicos no óleo}

A composição química dos constituintes voláteis teve sua análise realizada no laboratório Adolpho Ducke (LAD) no Museu Emílio Goeldi, Estado do Pará, por cromatografia em fase gasosa acoplada à espectrometria de massa (CG/EM), em sistema Shimadzu QP-2010 Plus, equipado com coluna DB-5MS (30m x $0,25 \mathrm{~mm} \times 0,25 \mu \mathrm{m}$ de espessura de filme). O gás de arraste usado foi o hélio com fluxo de $1,2 \mathrm{ml} / \mathrm{min}$. A injeção da amostra $(1 \mu \mathrm{L}$ da solução de $2 \mu \mathrm{L}$ de óleo em $1 \mathrm{~mL}$ de hexano) sem divisão de fluxo. A temperatura do injetor e da interface foi de $250^{\circ} \mathrm{C}$. O programa de temperatura do forno foi de $60-250^{\circ} \mathrm{C}$, utilizando-se uma rampa de $3^{\circ} \mathrm{C} / \mathrm{min}$. O espectrômetro de massas foi por impacto eletrônico a $70 \mathrm{eV}$ e a temperatura da fonte de íons a $220^{\circ} \mathrm{C}$. A identificação química foi realizada através da comparação dos espectros de massas e índices de retenção (IR) com os de substâncias padrão existentes nas bibliotecas do sistema e com dados da literatura (ADAMS, 2007). Os IRs foram obtidos utilizando a série homóloga dos n-alcanos.

\section{TRATAMENTO DOS RESULTADOS}

\subsection{Granulometria por peneiramento do material botânico}

Tabela 1 - Dados obtidos no processo de peneiramento

\begin{tabular}{|c|c|c|c|}
\hline \#Tyler & Massa vazia & Massa cheia & Diâmetro $(\mathbf{m m})$ \\
\hline $\mathbf{6}$ & 490 & 490,4 & 3,35 \\
\hline $\mathbf{9}$ & 419,4 & 439,2 & 2 \\
\hline $\mathbf{1 0}$ & 432,8 & 458,8 & 1,7 \\
\hline $\mathbf{1 2}$ & 452,8 & 483,8 & 1,4 \\
\hline $\mathbf{1 4}$ & 416 & 439,8 & 1,18 \\
\hline $\mathbf{2 0}$ & 514,6 & 578 & 0,85 \\
\hline $\mathbf{2 4}$ & 414,2 & 434,8 & 0,71 \\
\hline $\mathbf{2 8}$ & 309,4 & 326 & 0,6 \\
\hline $\mathbf{3 2}$ & 436 & 444,8 & 0,5 \\
\hline Fundo & 353,4 & 392,6 & 0 \\
\hline
\end{tabular}

A partir dos dados da Tabela 1 , determinou-se a massa retida, $\%$ retida, $\%$ passante, $\%$ retida acumulada e $\%$ passante acumulada. 


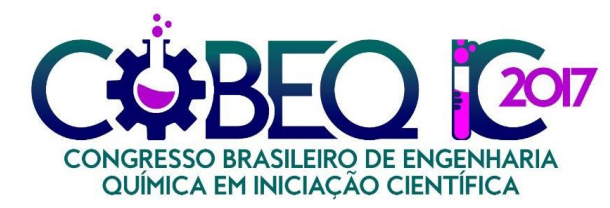

XII Congresso Brasileiro de Engenharia Química

em Iniciação Científica

UFSCar - São Carlos - SP

16 a 19 de Julho de 2017

Tabela 2 - Resultados obtidos no processo de peneiramento

\begin{tabular}{|c|c|c|c|c|}
\hline Massa retida & \%Retida & \%passante & \%r acumulada & \%p acumulada \\
\hline $\mathbf{0 , 4}$ & 0,16025641 & 99,83974359 & 0,16025641 & 99,83974359 \\
\hline $\mathbf{1 9 , 8}$ & 7,932692308 & 92,06730769 & 8,092948718 & 91,90705128 \\
\hline $\mathbf{2 6}$ & 10,41666667 & 89,58333333 & 18,50961538 & 81,49038462 \\
\hline $\mathbf{3 1}$ & 12,41987179 & 87,58012821 & 30,92948718 & 69,07051282 \\
\hline $\mathbf{2 3 , 8}$ & 9,53525641 & 90,46474359 & 40,46474359 & 59,53525641 \\
\hline $\mathbf{6 3 , 4}$ & 25,40064103 & 74,59935897 & 65,86538462 & 34,13461538 \\
\hline $\mathbf{2 0 , 6}$ & 8,253205128 & 91,74679487 & 74,11858974 & 25,88141026 \\
\hline $\mathbf{1 6 , 6}$ & 6,650641026 & 93,34935897 & 80,76923077 & 19,23076923 \\
\hline $\mathbf{8 , 8}$ & 3,525641026 & 96,47435897 & 84,29487179 & 15,70512821 \\
\hline $\mathbf{3 9 , 2}$ & 15,70512821 & 84,29487179 & 100 & \\
\hline
\end{tabular}

Com base na Tabela 2 foi possível calcular o diâmetro médio geral mostrado no Gráfico 1, dado pela intercessão das curvas, é aproximadamente $1,1 \mathrm{~mm}$.

Gráfico 1 - Diâmetro médio total

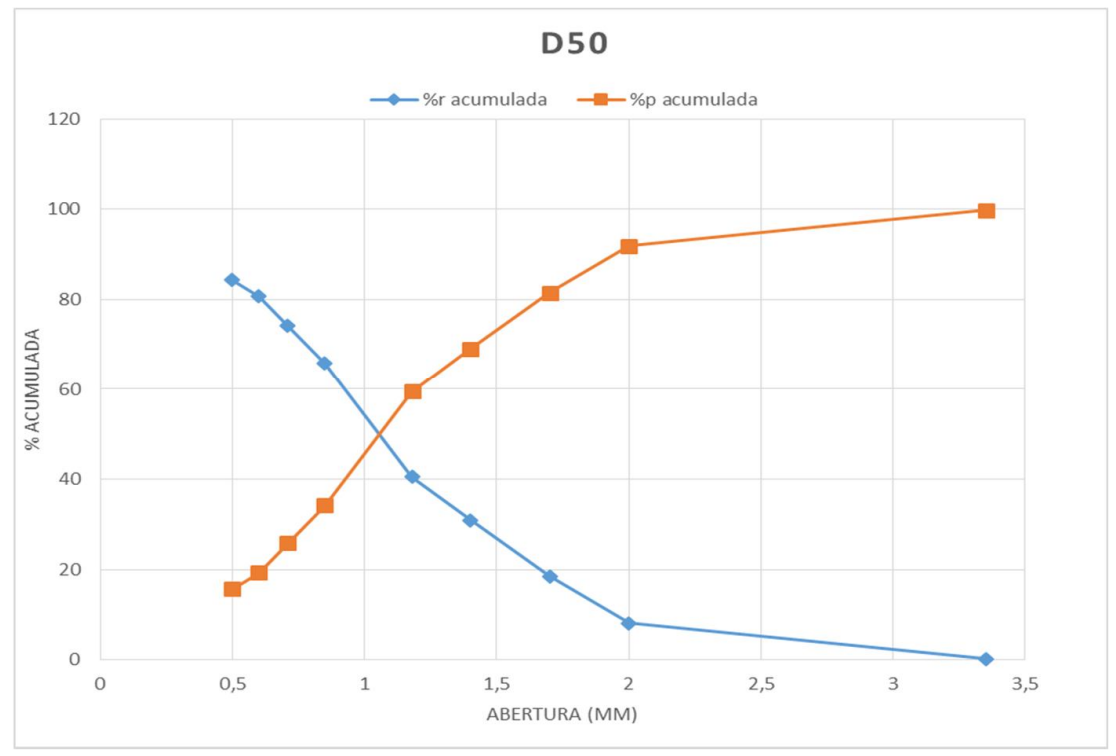

Com base nas análises feitas, utilizou-se: para o \#Tyler 6,9,10,12 a denominação "grossa", para o \#Tyler 14,20,24 a denominação "média" e para \#Tyler 28,32 e fundo, denominação "fina". Assim, o diâmetro médio de cada classificação está disposto na Tabela 3.

Tabela 3 - Diâmetro médio de cada classificação

\begin{tabular}{|l|l|l|l|}
\hline Classificação & Fina & Média & Grossa \\
\hline Diâmetro médio (mm) & 0,42 & 1,02 & 1,79 \\
\hline
\end{tabular}

\subsection{Rendimento da espécie Croton cajucara}

Feita a classificação, os rendimentos do óleo essencial extraído da espécie em questão estão apresentados na Tabela 4 em função de sua granulometria com $60 \mathrm{~g}$ de massa para os três casos. 
A partir da análise, obteve-se uma pequena diferença no rendimento para as medidas estudadas. É importante destacar que a cor do óleo essencial da espécie é caracterizada como amarelo.

Tabela 4 - Rendimento em função da granulometria

\begin{tabular}{|c|c|c|c|}
\hline Granulometria & Fina & Média & Grossa \\
\hline Umidade (\%) & 9,86 & 11,35 & 8,02 \\
\hline Rendimento & $1,1 \%$ & $1,3 \%$ & $1,26 \%$ \\
\hline
\end{tabular}

A granulometria titulada "média" obteve um maior rendimento em relação às demais. Porém, é importante observar que estatisticamente não há uma variação significativa nos resultados, concluindo que a granulometria não influencia no rendimento do objeto de estudo.

\subsection{Análise da composição química da espécie Croton cajucara}

Com base no método de Cromatografia em fase gasosa acoplada à espectrometria de massa (CG/EM) comparado com a literatura, foram identificados, como componentes voláteis majoritários da espécie Croton cajucara, o álcool monoterpênico Linalol, seguido dos sesquiterpenos Espatulenol e a-Gurjuneno (Tabela 5).

Tabela 5 - Composição química majoritária do óleo essencial da Croton cajucara

\begin{tabular}{|l|c|c|c|}
\hline \multicolumn{1}{|c|}{ CONSTITUINTES } & \multicolumn{3}{|c|}{ GRANULOMETRIA } \\
\hline MAJORITÁRIOS (\%) & FINA & MÉDIA & GROSSA \\
\hline Linalol & 24,52 & 28,63 & 16,39 \\
\hline $\boldsymbol{\alpha}$-Gurjuneno & 8,73 & 8,62 & 3,46 \\
\hline Espatulenol & 8,36 & 9,16 & 16,59 \\
\hline
\end{tabular}

E através do Gráfico 2 é possível perceber que, para o Linalol, a maior quantidade está presente na granulometria média; o $\alpha$-Gurjuneno, na granulometria fina e o Espatulenol, na granulometria grossa, indicando que há influência da granulometria na composição química.

Gráfico 2 - Componentes majoritários da Croton cajucara

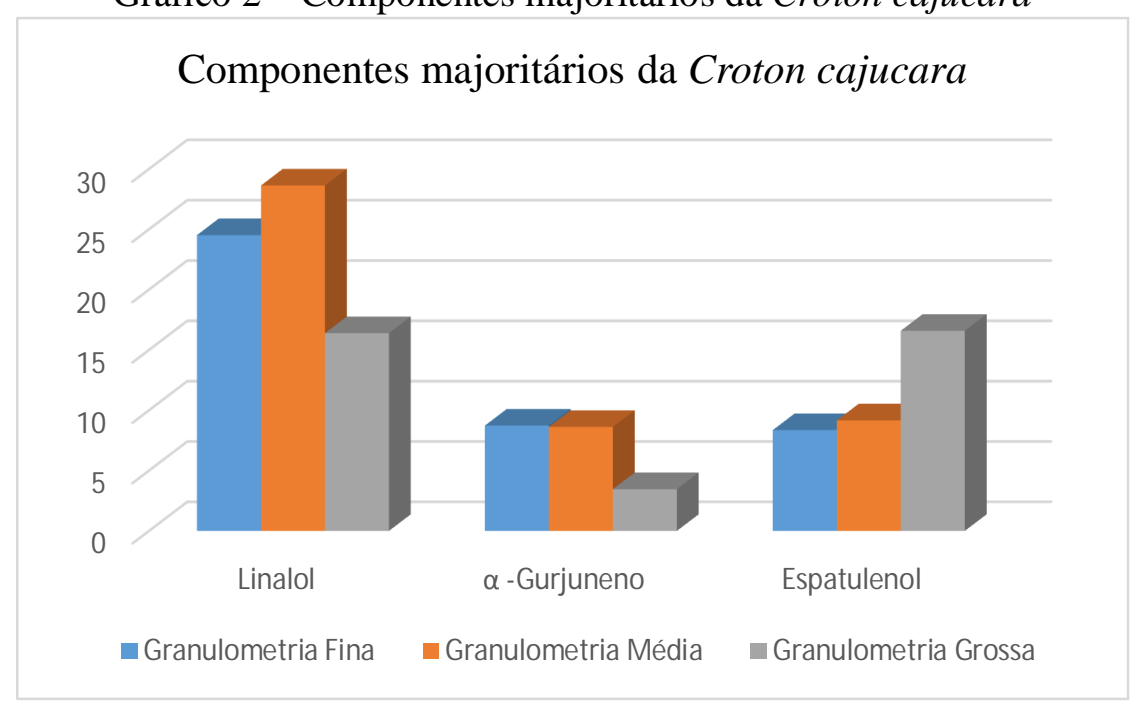




\section{CONCLUSÕES}

É possível concluir que não houve diferença significativa no rendimento do óleo essencial da Croton cajucara em função da granulometria. E a presença de sesquiterpenos (Espatulenol e $\alpha$ Gurjuneno) foi comprovada no OE. da casca do espécime, além do álcool monoterpênico majoritário Linalol. Somado ao nível distinto das concentrações, em percentual, dos constituintes com base em suas granulometrias.

\section{REFERENNCIAS}

BIGHETTI EJ,Hiruma-Lima CA, Gracioso JS, Souza Brito ARM 1999. Antiinflammatory and antinociceptive effects in rodents of the essential oil of Croton cajucara Benth. J EthnoPharmacol 51: 1447-1453. Ferreira MA, Souza MAA, Araujo OJL, Ferr

CASSEL, E.; VARGAS, R. M. F., MARTINEZ, N.; LORENZO, D.; DELLACASSA, E. Steam distillation modeling for essential oil extraction process. Industrial Crops and Products, v. 29, p. 171-176, 2009

COSTA M, Di Stasi LC, Kirizawa M,Mendacolli SL, Gomes C, Trolin G. Screening in mice of some medicinal plants used for analgesic purposes in the state of Sao Paulo. Part II. J Ethnopharmacol. 1989 Nov;27(1-2):25-33.

HIRUMA-Lima, C.A., Gracioso, J.S., Bighetti, E.J., Grassi- Kassisse, D.M., Nunes, D.S., Brito, A.R., 2002b. Effect of essential oil obtained from Croton cajucara Benth. ongastric ulcer healing and protective factors of the gastric mucosa.

HIRUMA-Lima, C.A., Gracioso, J.S., Rodriguez, J.A., Haun, M., Nunes, D.S., Souza Brito, A.R., 2000. Gastroprotective effect of essential oil from Croton cajucara Benth.(Euphorbiaceae). J. Ethnopharmacol. 69, 229-234.

HIRUMA-Lima, C.A., Toma, W., Gracioso Jde, S., de Almeida,A.B., Batista, L.M., Magri, L., de Paula, A.C., Soares,F.R., Nunes, D.S., Souza Brito, A.R., 2002a. Natural trans-crotonin: the antiulcerogenic effect of another diterpene Isolated from the bark of Croton cajucara Benth. Biol.Pharm. Bull. 25, 452-456.

MORAIS LAS. 2009. Influência dos fatores abióticos na composição química dos óleos essenciais. Horticultura Brasileira 27: S4050- S4063.

OROFINO, C.R. Operações unitárias I. Belém-Pa, 1980.

SIMÕES CMO; SPITZER V. 1999. Óleos voláteis. In: SIMÕES CMO. et al. Farmacognosia: da planta ao medicamento. Porto Alegre: Ed. Universidade-UFRGS; Florianópolis: Ed. da UFSC.p. 387-415.

SIMÕES JC, Silva AJR, Serruya H, Bentes MHS (1979) Desidrocrotonina, um norditerpeno de Croton cajucara Benth (Euphorbiaceae). Ciênc e Cult 31: 1140-1141

YUSOFF, Z. M.; NORDIN, M. N. N.; RAHIMAN, M. H. F.; ADNAN, R.; TAIB, M. N. Characterization of Down-Flowing Steam Distillation System using Step Test Analysis. IEEE CSGRC, p. 197-201, 2011. 